\title{
Metformin Rescues the Myocardium from Doxorubicin-Induced Energy Starvation and Mitochondrial Damage in Rats
}

\author{
Abdelkader E. Ashour, ${ }^{1}$ Mohamed M. Sayed-Ahmed, ${ }^{1}$ \\ Adel R. Abd-Allah, ${ }^{1}$ Hesham M. Korashy, ${ }^{1}$ Zaid H. Maayah, ${ }^{1}$ \\ Hisham Alkhalidi, ${ }^{2}$ Mohammed Mubarak, ${ }^{2}$ and Abdulqader Alhaider ${ }^{1}$ \\ ${ }^{1}$ Department of Pharmacology and Toxicology, College of Pharmacy, King Saud University, P.O. Box 2529, Riyadh 11451, Saudi Arabia \\ ${ }^{2}$ Department of Pathology, College of Medicine, King Saud University, Riyadh 11461, Saudi Arabia \\ Correspondence should be addressed to Abdulqader Alhaider, aqahaider@gmail.com
}

Received 21 November 2011; Revised 11 February 2012; Accepted 26 February 2012

Academic Editor: Martin-Ventura Jose Luis

Copyright () 2012 Abdelkader E. Ashour et al. This is an open access article distributed under the Creative Commons Attribution License, which permits unrestricted use, distribution, and reproduction in any medium, provided the original work is properly cited.

\begin{abstract}
Clinical use of doxorubicin (DOX) is limited by its cardiotoxic side effects. Recent studies established that metformin (MET), an oral antidiabetic drug, possesses an antioxidant activity. However, whether it can protect against DOX-induced energy starvation and mitochondrial damage has not been reported. Our results, in a rat model of DOX-induced cardiotoxicity, show that DOX treatment significantly increased serum levels of $\mathrm{LDH}$ and $\mathrm{CK}-\mathrm{MB}$, indicators of cardiac injury, and induced expression of hypertrophic gene markers. DOX also caused marked decreases in the cardiac levels of glutathione, CoA-SH and ATP, and mRNA expression of catalase and NQO-1. These biochemical changes were associated with myocardial histopathological and ultrastructural deteriorations, as observed by light and electron microscopy, respectively. Cotreatment with $\mathrm{MET}(500 \mathrm{mg} / \mathrm{kg})$ eliminated all DOX-induced biochemical, histopathological, and ultrastructural changes. These findings demonstrate that MET successfully prevents DOX-induced cardiotoxicity in vivo by inhibiting DOX-induced oxidative stress, energy starvation, and depletion of intramitochondrial CoA-SH.
\end{abstract}

\section{Introduction}

The clinical use of doxorubicin (DOX), an anthracycline antibiotic, can have both favorable and unfavorable consequences. On the one hand, DOX is one of the most potent antitumor agents available; on the other hand, its use is limited by development of dose-dependent cardiomyopathy involving cardiomyocyte apoptosis and myocardial fibrosis that may lead to congestive heart failure usually refractory to common medications [1]. Although there is a linear relationship between the cumulative dose received and the incidence of cardiotoxicity, cardiotoxicity may develop in some patients at doses below the generally accepted threshold level [2]. Considerable research has focused on elucidating the mechanisms of DOX-induced cardiomyopathy, aiming at finding ways to prevent the development of cardiotox- icity. Several mechanisms have been reported, including generation of free radicals and lipid peroxidation of cardiac membranes [3], myocyte damage induced by cardiac calcium overload [4], formation of DOX-iron complex [5], impaired myocardial adrenergic regulation, cellular toxicity of anthracycline metabolites [6], and inhibition of beta-oxidation of long chain fatty acids with the consequent depletion of cardiac ATP [7].

Because of the undisputed key role that DOX plays in the treatment of many neoplastic diseases, one of the research aims being pursued most intensively is the possibility of eliminating its cardiotoxicity or reducing it to an acceptable level. If the cardiac complications resulting from DOX could be prevented or at least reduced, higher doses could potentially be utilized, thereby increasing cancer cure rates. In this regard, various drugs, including L-carnitine [8], dexrazoxane 
[9], vitamin E [10], melatonin [11], and resveratrol [12], have been shown to protect against DOX-induced cardiotoxicity. Noticeably, a common theme among these therapeutic approaches is that free radical generation by DOX is being targeted. This highlights the critical role of oxidative stress in DOX-induced cardiac toxicity. This is supported by the findings demonstrating that DOX induces cardiomyocyte apoptosis by reactive oxygen species-dependent mechanism $[6,13]$. Interestingly, this pathway has been found to be distinct from apoptosis induced by DOX in tumor cells [14].

The prevalence of glucose intolerance is increased in patients with malignancy [15]. Marks and Bishop [16] have reported that patients with malignant disease had a significantly lower net rate of disappearance of glucose, compared with the control subjects. In addition, DOX itself, at therapeutic doses, has been reported to be highly toxic to endocrine function mainly on insulin secretion [17]. Moreover, glucocorticoids are often included with other agents in cancer treatment to prevent side effects $[18,19]$. However, administration of glucocorticoids is commonly associated with impairment of insulin sensitivity, elevations in peripheral glucose levels, and the suppression of the hypothalamicpituitary-adrenal axis [20]. Insulin resistance is correlated with an enhanced risk for cancer. In addition, the rate of tumor recurrence, metastatic spread, and fatal outcome is higher in cancer patients with hyperglycemia or type II diabetes, as compared with tumor patients without metabolic disease [21]. Taken together, all these previously mentioned findings emphasize the need for an adjuvant drug to be given along with DOX to patients with malignancy, in order to improve glucose tolerance and prevent DOX-induced cardiotoxicity.

Metformin (MET) is an oral biguanide antihyperglycemic drug that is widely used for the management of type 2 diabetes mellitus. Therapeutic effects of MET have been attributed to a combination of improved peripheral uptake and utilization of glucose, decreased hepatic glucose output, decreased rate of intestinal absorption of carbohydrates, and enhanced insulin sensitivity [22, 23]. Beyond its glucoselowering effects, MET has been shown to exhibit antioxidant properties in various tissues, an effect that is independent of its effect on insulin sensitivity and acts to decrease lipid peroxidation [24, 25]. Further, MET has been demonstrated to exert cardioprotective effects that could be due to its direct beneficial effects on cellular and mitochondrial function and therefore be independent of its insulin-sensitizing effect [26]. Noteworthy, MET has been recently shown to significantly improve left ventricular function and survival via activation of AMP-activated protein kinase (AMPK) in an in vivo murine model of heart failure [27].

Based on the aforementioned information, we hypothesized that MET, by virtue of its antioxidant and cardioprotective effects, can protect against DOX-induced cardiomyopathy. The overall objective of the present study was to determine the extent to which MET can protect against DOX-induced-energy starvation and mitochondrial damage and to determine the possible mechanism of this protection. Results from this study may shed the light on the usefulness of MET, as a safe, clinically approved drug, in such pathological situations.

\section{Materials and Methods}

2.1. Animals. Adult male Wistar albino rats, weighing 230 $250 \mathrm{~g}$, were obtained from the Animal Care Center, College of Pharmacy, King Saud University, Riyadh, Saudi Arabia. Animals were housed in metabolic cages under controlled environmental conditions $\left(25^{\circ} \mathrm{C}\right.$ and a $12 \mathrm{~h} \mathrm{light/dark} \mathrm{cycle)}$. Animals had free access to pulverized standard rat pellet diet. The protocol of this study has been approved by the Research Ethics Committee of College of Pharmacy, King Saud University, Riyadh, Saudi Arabia.

2.2. Chemicals. DOX was a generous gift from the King Khalid University Hospital drug store. MET, acetyl-CoA, $\mathrm{CoA}-\mathrm{SH}$, adenosine triphosphate, and adenosine diphosphate were purchased from Sigma Chemical Company (St. Louis, MO, USA). TRIzol reagent was purchased from Invitrogen Co. (Grand Island, NY, USA). The high-capacity cDNA reverse transcription kits and SYBR Green PCR Master Mix were purchased from Applied Biosystems (Foster City, CA, USA). Metformin was dissolved in normal saline and administered orally at low dose $(100 \mathrm{mg} / \mathrm{kg})$ and high dose $(500 \mathrm{mg} / \mathrm{kg})$. All other chemicals were of the highest commercially available analytical grade.

2.3. Experimental Design and Treatment Protocol. In this study, the DOX treatment regimen used to develop the cumulative cardiotoxicity was adopted from Beanlands et al. [28] and Sayed-Ahmed et al. [29], while MET dosages (50 and $500 \mathrm{mg} / \mathrm{kg}$, p.o.) were selected based on studies by Anurag and Anuradha [30] and Wang et al. [31], respectively. A total of 60 adult male Wistar albino rats were randomly divided into 6 groups of 10 animals each. In the first group, animals were injected intraperitoneally (i.p.) with normal saline $(2.5 \mathrm{~mL} / \mathrm{kg})$ and served as a normal control. Animals in the second group were injected, every other day, with DOX $(3 \mathrm{mg} / \mathrm{kg}$, i.p.) over a period of 11 days to obtain cumulative dose of $18 \mathrm{mg} / \mathrm{kg}$. Animals in the third and fourth groups received MET (50, $500 \mathrm{mg} / \mathrm{kg}$, p.o., daily), respectively, over a period of 11 days. Animals in the fifth group were injected every other day with DOX $(3 \mathrm{mg} / \mathrm{kg}$, i.p. $)$ as in group 2 and daily treated with MET $(50 \mathrm{mg} / \mathrm{kg}$, p.o.) over a period of 11 days. Animals in group 6 were injected every other day with DOX $(3 \mathrm{mg} / \mathrm{kg}$, i.p. $)$ as in group 2 and daily treated with MET $(500 \mathrm{mg} / \mathrm{kg}$, p.o.) over a period of 11 days. Twentyfour hours after receiving the last dose of DOX, animals were anesthetized with light ether anesthesia, and blood samples were obtained from the retro-orbital sinus of the eye. Serum was separated for measurement of lactate dehydrogenase (LDH) and creatine phosphokinase iso-enzyme MB (CKMB). Immediately after collection of blood samples, animals were sacrificed and hearts were quickly excised, washed with saline, blotted with a filter paper, and homogenized as indicated in the procedures of measurement of each parameter, using a Branson homogenizer (250, VWR Scientific, Danbury, CT., USA). 
2.4. Assessment of Serum Levels of Cardiac Enzymes. Serum levels of $\mathrm{LDH}$ and CK-MB were determined according to the methods of Buhl and Jackson [32] and Wu and Bowers [33], respectively.

2.5. Determination of CoA-SH and Acetyl-CoA in Isolated Rat Heart Mitochondria. Free CoA-SH and acetyl-CoA were determined in isolated rat heart mitochondria using HPLC as described previously [34]. Briefly, mitochondria were mixed with ice-cold $6 \%$ perchloric acid and centrifuged at $300 \times \mathrm{g}$ for $5 \mathrm{~min}$ at $0.5^{\circ} \mathrm{C}$. The resulting supernatant fluid was neutralized to $\mathrm{pH}$ 6-7 and then injected into the HPLC apparatus. Chromatographic separation was performed using ODS-Hypersil, $150 \times 4.6 \mathrm{~mm}$ i.d., $5 \mu \mathrm{m}$ column (Supelco SA, Gland, Switzerland). The UV detector was adjusted at $254 \mathrm{~nm}$ and set at 0.005 . A mobile phase of $220 \mathrm{mM}$ potassium phosphate, containing $0.05 \%$ dithioglycol (A) and $98 \%$ methanol $/ 2 \%$ chloroform (B), was used. The flow rate was $0.6 \mathrm{~mL} / \mathrm{min}$, and the gradient was as follows: at zero time, $94 \% \mathrm{~A}$ and $6 \% \mathrm{~B}$; at $8 \mathrm{~min}, 92 \% \mathrm{~A}$ and $8 \% \mathrm{~B}$; at $14 \mathrm{~min}, 87 \%$ $\mathrm{A}$ and $13 \% \mathrm{~B}$; at $25 \mathrm{~min}, 80 \% \mathrm{~A}$ and $20 \% \mathrm{~B}$; at $40 \mathrm{~min}, 55 \%$ $\mathrm{A}$ and $45 \% \mathrm{~B}$; at $60 \mathrm{~min}, 94 \% \mathrm{~A}$ and $6 \% \mathrm{~B}$.

2.6. Measurement of Adenosine Triphosphate in Cardiac Tissue. Adenosine triphosphate (ATP) was determined in heart tissues using high-performance liquid chromatography (HPLC) as described by Botker et al. [35]. In brief, heart tissue was homogenized in ice-cold $6 \%$ perchloric acid and centrifuged at $3000 \mathrm{rpm}$ for $15 \mathrm{~min}$ at $0.5^{\circ} \mathrm{C}$, and the supernatant fluid was injected into the HPLC system (Kontron Instrument, Milano, Italy) after neutralization to $\mathrm{pH}$ 6-7. Chromatographic separation was performed at a flow rate of $1.2 \mathrm{~mL} / \mathrm{min}$, using ODS-Hypersil, $150 \times 4.6 \mathrm{~mm}$ I.D., $5 \mu \mathrm{m}$ column (Supelco SA, Gland, Switzerland) and $75 \mathrm{mM}$ ammonium dihydrogen phosphate as the mobile phase. The peak elution was followed at $254 \mathrm{~nm}$.

2.7. Determination of Reduced Glutathione in Cardiac Tissues. Cardiac tissue levels of the acid-soluble thiols, mainly reduced glutathione (GSH), were assayed spectrophotometrically at $412 \mathrm{~nm}$, according to the method of Ellman [36]. The contents of GSH were expressed as $\mu \mathrm{mol} / \mathrm{g}$ wet tissue.

2.8. Histopathology and Electron Microscopy. The heart tissues from all studied groups of rats were analyzed at both histopathological and electron microscopic levels. Threemicron thick sections were performed on the formalin-fixed, paraffin-embedded tissue of the heart, and the sections were stained with routine hematoxylin and eosin stains (H\&E). The sections were studied under the optic routine microscope by the histopathologists involved in the study.

The heart tissues submitted for electron microscopy examination were fixed in 3\% glutaraldehyde. The tissues were embedded in osmium tetroxide, and the semithin sections were stained with toluidine blue. The adequacy of the sample in each case was checked on the semithin sections. The thin sections were stained with uranyl acetate and lead citrate, then all the sections were examined and photographed by the same histopathologists.
2.9. RNA Preparation and Quantitative Real-Time PCR. To determine the effect of DOX and/or MET on mRNA expression levels of cardiac hypertrophic gene markers $(\alpha$-MHC and $\beta$-MHC) and oxidative stress-mediated genes (glutathione S-transferase- $\alpha$ (GST $\alpha$ ), catalase (CAT), $\mathrm{NAD}(\mathrm{P}) \mathrm{H}$ :quinone oxidoreductase 1 (NQO1) and heme oxygenase 1 (HO-1)), we conducted quantitative real-time polymerase chain reaction (qRT-PCR), as follows.

2.9.1. RNA Extraction and cDNA Synthesis. Total RNA from the heart tissue homogenate was isolated using TRIzol reagent (Invitrogen) according to the manufacturer's instructions and quantified by measuring the absorbance at $260 \mathrm{~nm}$; the RNA quality was determined by measuring the 260/280 ratio. Thereafter, first strand cDNA synthesis was performed using the high-capacity cDNA reverse transcription kit (Applied Biosystems), according to the manufacturer's instructions. Briefly, $1.5 \mu \mathrm{g}$ of total RNA from each sample was added to a mix of $2.0 \mu \mathrm{L}$ of $10 \mathrm{x}$ reverse transcriptase buffer, $0.8 \mu \mathrm{L}$ of $25 \mathrm{x}$ dNTP mix $(100 \mathrm{mM})$, $2.0 \mu \mathrm{L}$ of $10 \mathrm{x}$ reverse transcriptase random primers, $1.0 \mu \mathrm{L}$ of MultiScribe reverse transcriptase, and $3.2 \mu \mathrm{L}$ of nuclease-free water. The final reaction mix was kept at $25^{\circ} \mathrm{C}$ for $10 \mathrm{~min}$, heated to $37^{\circ} \mathrm{C}$ for $120 \mathrm{~min}$, heated for $85^{\circ} \mathrm{C}$ for $5 \mathrm{~s}$, and finally cooled to $4^{\circ} \mathrm{C}$.

2.9.2. Quantification of $m R N A$ Expression by $q R T-P C R$. Quantitative analysis of mRNA expression of target genes was performed by RT-PCR through subjecting the resulting cDNA to PCR amplification using 96-well optical reaction plates in the ABI Prism 7500 System (Applied Biosystems). The $25 \mu \mathrm{L}$ reaction mix contained $0.1 \mu \mathrm{L}$ of $10 \mu \mathrm{M}$ forward primer and $0.1 \mu \mathrm{L}$ of $10 \mu \mathrm{M}$ reverse primer ( $40 \mathrm{nM}$ final concentration of each primer), $12.5 \mu \mathrm{L}$ of SYBR Green Universal Master Mix, $11.05 \mu \mathrm{L}$ of nuclease-free water, and $1.25 \mu \mathrm{L}$ of cDNA sample. The primers used in the current study are listed in Table 1. Assay controls were incorporated onto the same plate, namely, no-template controls to test for the contamination of any assay reagents. The real-time PCR data were analyzed using the relative gene expression (i.e., $\Delta \Delta \mathrm{CT}$ ) method, as described in Applied Biosystems User Bulletin no. 2. Briefly, the data are presented as the fold change in gene expression normalized to the endogenous reference gene $\beta$ actin and relative to a calibrator.

2.10. Statistical Analysis. The data are expressed as mean \pm standard error of the mean (SEM). The significance of differences among groups was evaluated with one-way analysis of variance (ANOVA) followed by the Tukey-Kramer multiple comparison test. $P$ values of 0.05 or less were considered significant.

\section{Results}

3.1. MET Protects against DOX-Induced Cardiac Myocyte Injury. Table 2 shows the effects of DOX, MET, and DOX plus MET on the serum level of cardiotoxicity enzymatic indices, CK-MB and LDH, in rats. Administration of DOX $(3 \mathrm{mg} / \mathrm{kg})$ every other day over a period of 11 days resulted 
TABle 1: Primers sequences used for real-time PCR reactions.

\begin{tabular}{lll}
\hline Primer set & Sense primer $5^{\prime} \rightarrow 3^{\prime}$ & Antisense primer $5^{\prime} \rightarrow 3^{\prime}$ \\
\hline$\alpha$-MHC & GGACCACCCATCCTCACTTT & AGCCTCTCATCTCGCATCTC \\
$\beta$-MHC & ACCGCTGAGACAGAGAATGG & GGGTTGGCTTGGATGATTT \\
GST $\alpha$ & GCTTTACTGTGCAAGGGAGACA & GGAAGGAGGATTCAAGTCAGGA \\
CAT & CCCGAGTCCAGGCTCTTCT & CGGCCTGTACGTAGGTGTGA \\
NQO 1 & CGCAGACCTTGTGATATTCCAG & TGTTGCGCTCAATCTCCTCCT \\
HO- 1 & ATGGCCTCCCTGTACCACATC & CGTTTCTTCCATCCTTCCAGG \\
$\beta$-Actin & CTGGCACCCAGGACAATG & GCCGATCCACACGGAGTA \\
\hline
\end{tabular}

TABLE 2: The protective effect of MET against DOX-induced cardiac myocyte injury.

\begin{tabular}{lcc}
\hline Treatment group & CK-MB (U/L) & LDH (U/L) \\
\hline Control & $331 \pm 16$ & $342 \pm 35$ \\
DOX & $1125 \pm 94^{*}$ & $1299 \pm 122^{*}$ \\
MET, $50 \mathrm{mg} / \mathrm{kg}$ & $342 \pm 24^{\#}$ & $375 \pm 25^{\#}$ \\
MET, $500 \mathrm{mg} / \mathrm{kg}$ & $349 \pm 36^{\#}$ & $354 \pm 32^{\#}$ \\
DOX + MET, $50 \mathrm{mg}$ & $903 \pm 69^{*}$ & $1030 \pm 67^{*}$ \\
DOX + MET, $500 \mathrm{mg}$ & $439 \pm 47^{\#}$ & $417 \pm 36^{\#}$ \\
\hline
\end{tabular}

All data represent mean values $\pm \operatorname{SEM}(n=10)$.

*indicates significant change from control, at $P<0.05$.

\# indicates significant change from DOX, at $P<0.05$.

TABle 3: MET rescues the myocardium from DOX-induced depletion of intramitochondrial CoA-SH.

\begin{tabular}{lcc}
\hline Treatment groups & $\begin{array}{c}\text { CoA-SH }(\mathrm{nmol} / \mathrm{mg} \\
\text { protein) }\end{array}$ & $\begin{array}{c}\text { Acetyl-CoA } \\
\text { (nmol/mg protein })\end{array}$ \\
\hline Control & $3.26 \pm 0.16$ & $13.41 \pm 0.62$ \\
DOX & $1.89 \pm 0.24^{*}$ & $22.31 \pm 0.89^{*}$ \\
MET, $50 \mathrm{mg} / \mathrm{kg}$ & $2.91 \pm 0.29^{\#}$ & $12.19 \pm 0.59^{\#}$ \\
MET, $500 \mathrm{mg} / \mathrm{kg}$ & $4.22 \pm 0.20^{* \#}$ & $8.01 \pm 0.40^{* \#}$ \\
DOX + MET, $50 \mathrm{mg} / \mathrm{kg}$ & $2.77 \pm 0.16$ & $19.28 \pm 0.93^{*}$ \\
DOX + MET, $500 \mathrm{mg} / \mathrm{kg}$ & $3.06 \pm 0.18^{\#}$ & $15.44 \pm 0.78^{\#}$ \\
\hline
\end{tabular}

All data represent mean values $\pm \operatorname{SEM}(n=10)$.

* indicates significant change from control, at $P<0.05$.

\# indicates significant change from DOX, at $P<0.05$.

in a significant $240 \%$ and $280 \%$ increases in serum LDH and $\mathrm{CK}-\mathrm{MB}$, respectively, as compared to the control group. Treatment with MET at dose level either $50 \mathrm{mg} / \mathrm{kg}$ or $500 \mathrm{mg} / \mathrm{kg}$ for 11 successive days showed nonsignificant changes as compared to the control group. Interestingly, daily administration of MET $(500 \mathrm{mg} / \mathrm{kg}$ ) to DOX-treated rats resulted in a complete reversal of DOX-induced increase in serum CK-MB and $\mathrm{LDH}$ to the control values. However, administration of the small dose of MET ( $50 \mathrm{mg} / \mathrm{kg}$ ) did not prevent DOX-induced increase in cardiac enzymes.

3.2. MET Rescues the Myocardium from DOX-Induced Depletion of Intramitochondrial CoA-SH. The effects of DOX, MET, and DOX plus MET on the level of CoA-SH and acetylCoA in isolated rat heart mitochondria are shown in Table 3. Treatment with DOX resulted in a significant $42 \%$ decrease in CoA-SH level and a significant 66\% increase in acetyl-CoA in isolated rat heart mitochondria as compared to the control group. Treatment with MET $(500 \mathrm{mg} / \mathrm{kg}$ ) alone resulted in a significant $30 \%$ and $123 \%$ increase in CoA-SH level and a significant $40 \%$ and $45 \%$ decrease in acetyl-CoA as compared to the control and DOX groups, respectively. Interestingly, daily administration of the high dose of MET ( $500 \mathrm{mg} / \mathrm{kg}$ ) to DOX-treated rats resulted in a complete prevention of DOXinduced decrease in CoA-SH and increase in acetyl-CoA to the control values.

3.3. MET Protects the Myocardium against DOX-Induced Energy Starvation. Figure 1 shows the effects of DOX, MET, and DOX plus MET on ATP level in cardiac tissues. Treatment with a total cumulative dose of DOX $(18 \mathrm{mg} / \mathrm{kg}) \mathrm{re}-$ sulted in a significant decrease $(31.5 \%)$ in ATP level in cardiac tissues as compared to the control group. However, treatment with MET $(500 \mathrm{mg} / \mathrm{kg}$ ) for 11 successive days caused a significant increase (54\%) in ATP as compared to the control group. Interestingly, daily administration of MET $(500 \mathrm{mg} / \mathrm{kg})$ to DOX-treated rats resulted in a complete reversal of DOX-induced decrease in ATP to the control values. However, administration of the small dose of MET $(50 \mathrm{mg} / \mathrm{kg})$ did not alter DOX-induced decrease in ATP level in cardiac tissues.

3.4. MET Reverses the Effect of DOX on Cardiac GSH Level. Figure 2 shows the effects of DOX, MET, and DOX plus MET on GSH level in rat cardiac tissues. Treatment with a total cumulative dose of DOX $(18 \mathrm{mg} / \mathrm{kg})$ resulted in a significant $57 \%$ decrease in GSH level, as compared to the control group. Treatment with MET at dose level either $50 \mathrm{mg} / \mathrm{kg}$ or $500 \mathrm{mg} / \mathrm{kg}$ for 11 successive days resulted in a significant and dose-dependent (70\% and 102\%) increase in GSH level, respectively, as compared to the control group. Daily administration of MET either $50 \mathrm{mg} / \mathrm{kg}$ or $500 \mathrm{mg} / \mathrm{kg}$ to DOX-treated rats resulted in a complete reversal of DOXinduced decrease in cardiac GSH level to the control values.

3.5. Histopathology and Electron Microscopy. The light microscopic examination of the normal control rat hearts showed normal architecture and cytological features (Figure 3(i)). However, examination of the heart tissues of DOX-alone-treated rats revealed focal mild inflammation of the myocardium (arrows in Figure 3(ii)) that was associated with myocardial fiber injury, in addition to vacuolar changes of the cytoplasm of some myocardial cells 
(arrow in Figure 3(ii) B). The inflammatory infiltrate consisted of lymphocytes, plasma cells, and histiocytes, with prominent mononuclear chronic inflammatory appearance that replaced the degenerated myocardial muscle fibers with apparent hypereosinophilia (Figure 3(ii) A and B). Treatment with MET alone (50 or $500 \mathrm{mg} / \mathrm{kg}$ ) showed no pathological changes in the tested heart tissues, while, in the group that received MET $(50 \mathrm{mg} / \mathrm{kg})$ and DOX, the heart tissues showed few mild inflammatory foci with undetected myocardial injury (Figure 3(iii) A and B). The heart tissues of the rats that received MET $(500 \mathrm{mg} / \mathrm{kg}$ ) and DOX revealed almost normal morphological tissue appearance without any detected inflammation or tissue injury (Figure 3(iv) A and $\mathrm{B}$ ).

The electron microscopic examination of normal control rat hearts revealed normal mitochondria (arrow in Figure 4(i) A) with preserved internal architectures and surrounding organized myofibrils (arrow in Figure 4(i) B). The heart tissues of DOX-treated rats exhibited a prominent component of patchy myofibrillar loss and disarray, in addition to prominent hypercontraction bands with prominent $\mathrm{A}$ band loss (Figure 4(ii) A and B). Moreover, the mitochondria showed remarkable abnormalities that included enlargement, contour irregularities, increased spacing between the cristae and disruption of the internal architecture (arrow in Figure 4(ii) B). The group of rats treated with $50 \mathrm{mg} / \mathrm{kg}$ or $500 \mathrm{mg} / \mathrm{kg}$ of MET illustrated no significant ultrastructural changes. Hearts of rats treated with MET $(50 \mathrm{mg} / \mathrm{kg})$ and DOX showed some focal but prominent pathological findings. In this focus, there was an evidence of loss of myofibrils in addition to mitochondrial size and shape variation and many dilated lysosomes (arrow in Figure 4(iii) A). On the contrary, a significant improvement was seen in the ultrastructure of the hearts of rats treated with MET $500 \mathrm{mg} / \mathrm{kg}$ and DOX (Figure 4(iv) A and B). The examined sections showed a normal mitochondrial size and shape with normal arrangement of cristae.

3.6. MET Reverses DOX-Mediated Changes in the Levels of Cardiac Hypertrophic Genes. To investigate the effect of MET on the expression of cardiac hypertrophic gene markers, $\alpha$-MHC and $\beta$-MHC mRNA levels were determined in both healthy and DOX-induced cardiotoxic rats using RTPCR. Figure 5 shows that both doses of MET did not significantly alter the mRNA expression of both $\alpha$-MHC and $\beta$-MHC. On the other hand, DOX-treated rats showed a significant decrease in the mRNA level of $\alpha$-MHC by approximately $40 \%$, whereas $\beta$-MHC mRNA level was induced dramatically $250 \%$. Importantly, administration of MET significantly restored DOX-mediated changes in hypertrophic genes, which was more pronounced at the highest dose $(500 \mathrm{mg} / \mathrm{kg})$.

3.7. MET Restores DOX-Mediated Changes in the Levels of Oxidative Stress-Related Genes. To further explore the role of oxidative stress in the cardioprotective effect of MET, we have investigated the effect of MET on the expression of four oxidative stress-mediated genes, GST $\alpha$, CAT, NQO1, and HO-1. Figure 6 showed that induction of cardiotoxicity by

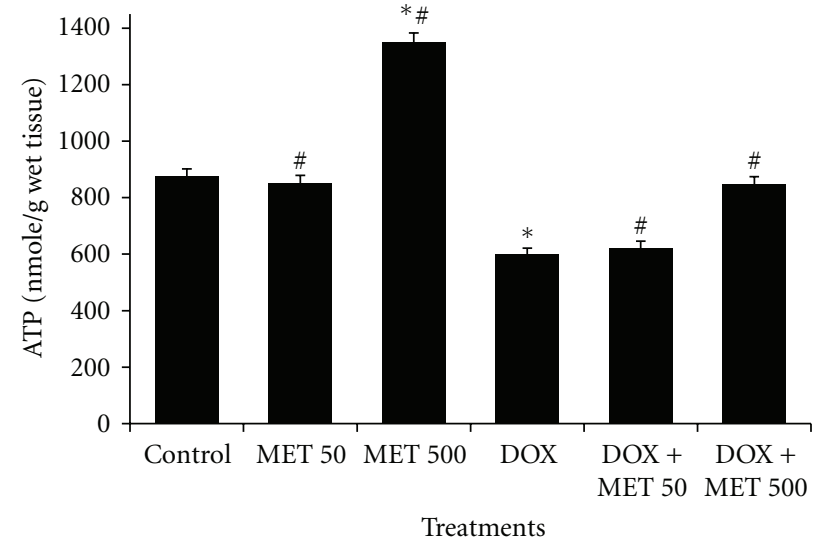

FIGURE 1: MET protects the myocardium against DOX-induced energy starvation. Rats $(n=10 /$ per treatment type $)$ received normal saline, DOX in a total cumulative dose of $18 \mathrm{mg} / \mathrm{kg}$, MET ( 50 or $500 \mathrm{mg} / \mathrm{kg}$, p.o., daily), or DOX plus either dose of MET. $24 \mathrm{~h}$ after receiving the last dose of DOX, ATP was determined in heart tissues using HPLC. Data are presented as mean \pm SEM $(n=10) . *$ and $\#$ indicate significant change from control and DOX, respectively, at $P<0.05$ using ANOVA followed by the TukeyKramer as a post-ANOVA test.

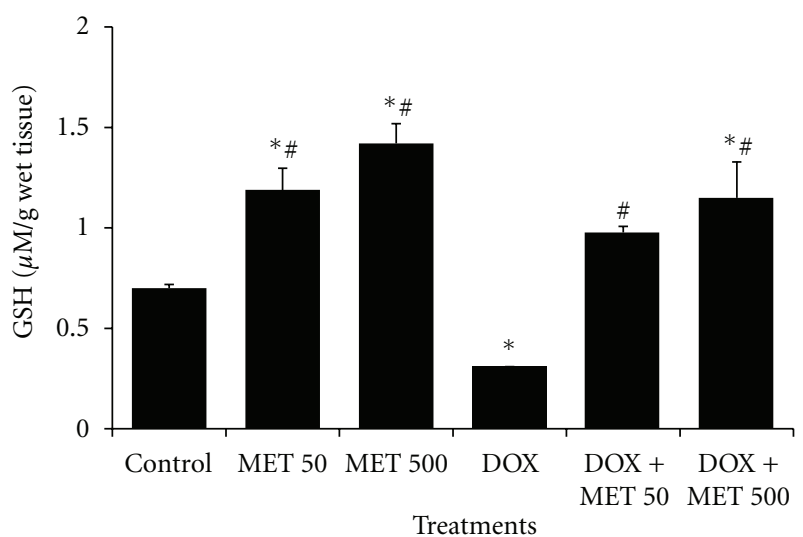

FIgURE 2: MET reverses the effect of DOX on cardiac GSH level. Rats ( $n=10 /$ treatment type) received normal saline, DOX in a total cumulative dose of $18 \mathrm{mg} / \mathrm{kg}$, MET (50 or $500 \mathrm{mg} / \mathrm{kg}$, p.o., daily) or DOX plus either dose of MET. $24 \mathrm{~h}$ after receiving the last dose of DOX, cardiac tissue level of GSH was determined in rat cardiac tissues. Data are presented as mean $\pm \operatorname{SEM}(n=10)$. $*$ and \# indicate significant change from control and DOX, respectively, at $P<0.05$ using ANOVA followed by the Tukey-Kramer as a postANOVA test.

DOX was associated with upregulated expression of GST $\alpha$ (A) and HO-1 (B) which was accompanied with a significant decrease in CAT (C) and NQO1 (D) mRNA expression levels as compared to control rats. Although treatment of control rats with MET did not alter the expression of most target genes, treatment of DOX-treated rats with MET significantly restored the DOX-induced modulations of all tested genes in a dose-dependent manner, in that MET induced NQO1 and CAT whereas inhibited GST $\alpha$ and HO-1 mRNA expression in a dose-dependent manner. 
$100 \mathrm{x}$

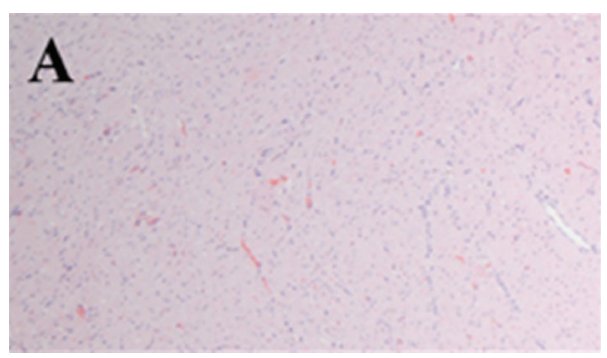

400x

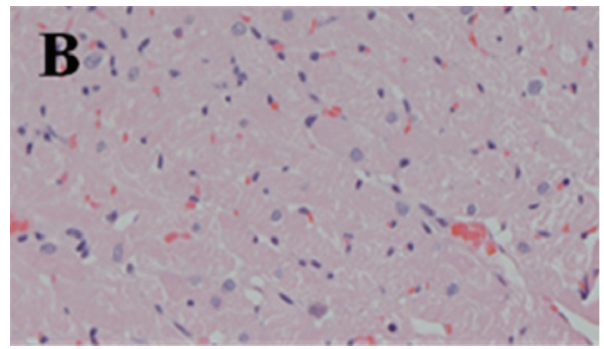

(i)

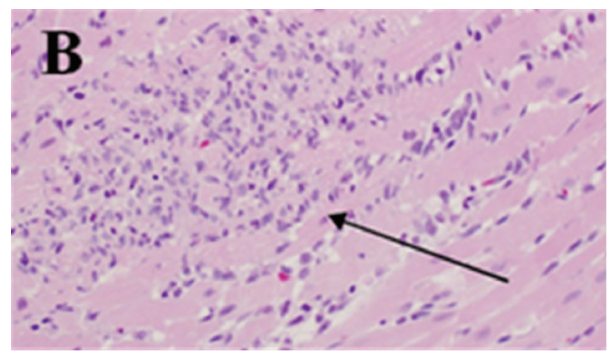

(ii)
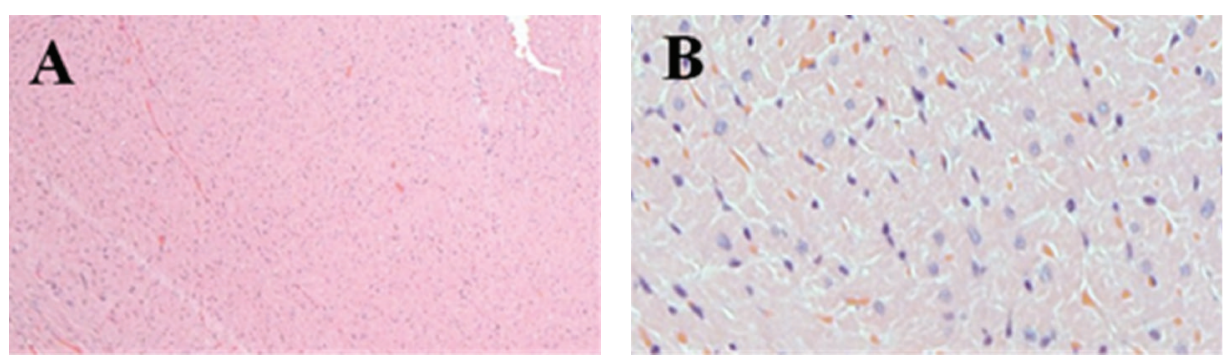

(iii)
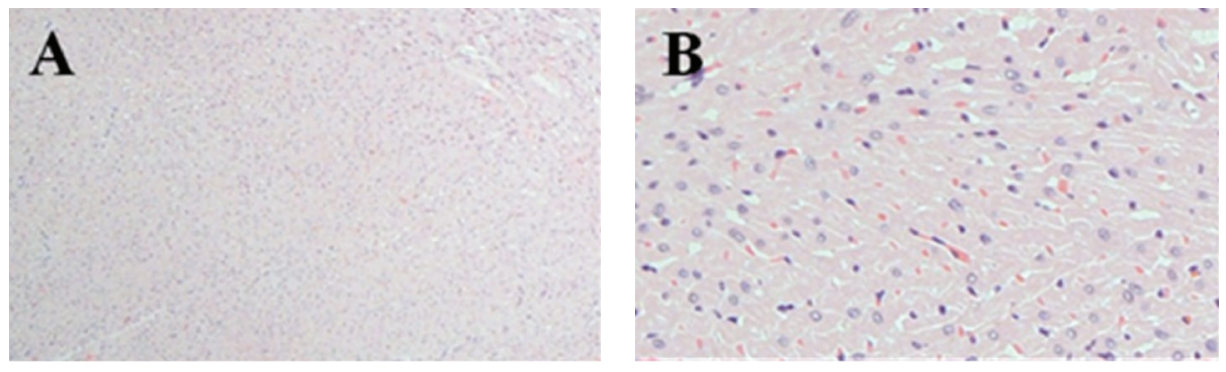

(iv)

FIgURE 3: MET protects myocardium against DOX-induced histopathological deteriorations. Photos (i) A and B show normal cardiac structure derived from normal control rat. Photos (ii) A and B are derived from heart section of a rat treated with a total cumulative dose of $18 \mathrm{mg} / \mathrm{kg}$ DOX and shows myocardial fiber injury as vacuolar changes of the cytoplasm and inflammatory infiltrate consisting of lymphocytes, plasma cells and histiocytes (arrow). Photos (iii) A and B show heart sections derived from a rat treated with MET 50 mg/kg prior to a total cumulative dose of $18 \mathrm{mg} / \mathrm{kg}$ DOX. It shows few inflammatory foci with considerable improvement in heart histology. Photos (iv) A and B illustrate heart sections obtained from a rat pretreated with MET $500 \mathrm{mg} / \mathrm{kg}$ before a total cumulative dose of $18 \mathrm{mg} / \mathrm{kg}$ DOX, revealing almost normal histology with a marked improvement in heart histology. Magnification, 400x in A; 100x in B.

\section{Discussion}

The most common hypothesis for the mechanism of DOXinduced cardiac injury is the increase of oxidative stress. Free radical generation by DOX, which is usually associated with a depression of GSH in heart tissue, results in disruption of cellular membrane integrity. This hypothesis is supported by the several reports that have shown that antioxidants, including vitamins $\mathrm{E}$ and $\mathrm{A}$, resveratrol, and selenium, protect cardiomyocytes against the toxicity of DOX [37]. On the 

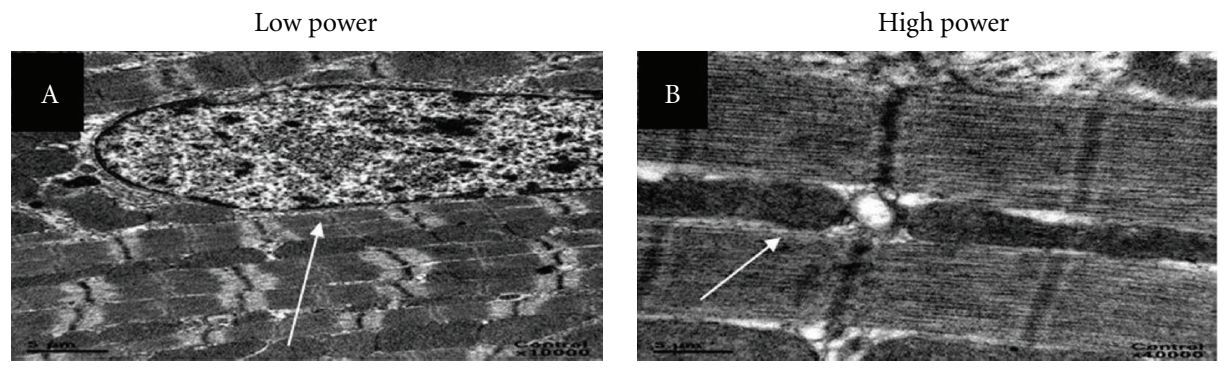

(i)
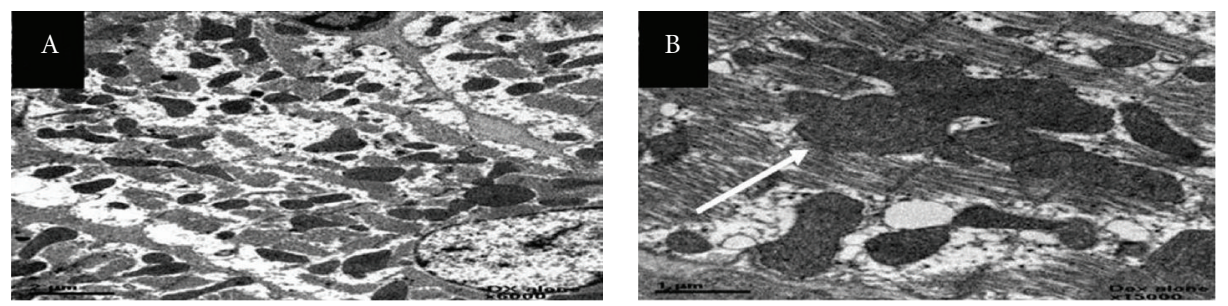

(ii)
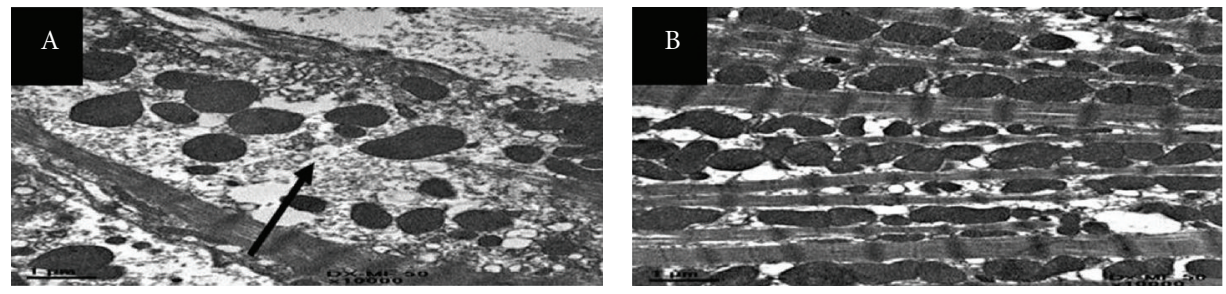

(iii)
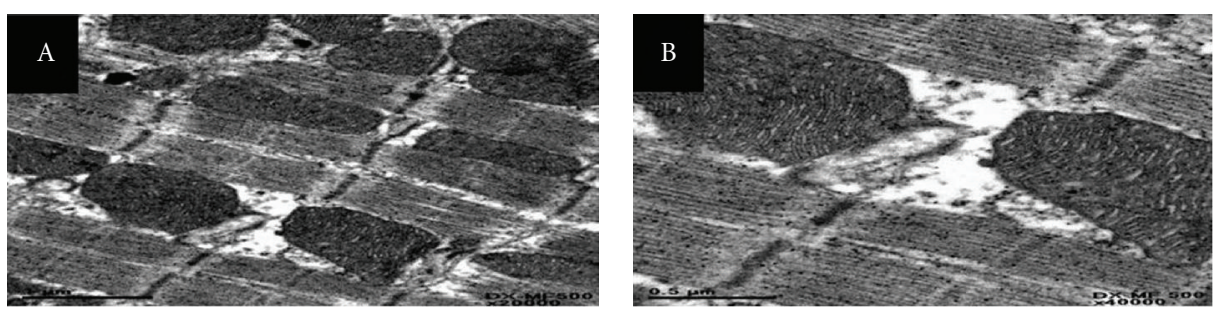

(iv)

FIgURE 4: MET protects myocardium against DOX-induced ultrastructural deteriorations. Photos (i) A and B show normal ultrastructure of a normal control rat heart. Photos (ii) A and B are EM photo taken for a heart section from a rat treated with a total cumulative dose of $18 \mathrm{mg} / \mathrm{kg}$ DOX and show a prominent component of patchy myofibrillar loss and disarray, hypercontraction bands with prominent A band loss. They also show mitochondrial abnormalities, including enlargement and irregular contour. Photos (iii) A and B are photos of ultrastructure of rat heart treated with MET $50 \mathrm{mg} / \mathrm{kg}$ prior to a total cumulative dose of $18 \mathrm{mg} / \mathrm{kg}$ DOX and show mild improvement in the mitochondrial structure. Photos (iv) A and B are photos of ultrastructure of cardiac muscle derived from a rat treated with MET $500 \mathrm{mg} / \mathrm{kg}$ prior to a total cumulative dose of $18 \mathrm{mg} / \mathrm{kg}$ DOX, showing almost normal ultrastructure, size, and shape of the myocardial fibers. Magnification, low power in A; high power in B.

other hand, impairment of cardiac high-energy phosphate metabolism has been recognized as an important feature of both acute and chronic DOX cardiotoxic action. These energetic deficits have been associated with compromised mitochondrial function [38]. In this context, oxidative damage to cardiac mitochondria and to cardiomyocytes has been widely implicated as a primary cause for doxorubicininduced cardiac toxicity $[39,40]$. The enhanced generation of ROS by DOX may directly damage mitochondria or alter the synthesis of proteins associated with the mitochondrial elec- tron transport chain, with the subsequent inhibition of oxidative phosphorylation and decrease in cardiac high-energy phosphate homeostasis $[41,42]$. The accumulation of various deficiencies in high-energy phosphate metabolism may be a very critical step for the DOX-induced deterioration of cardiac function and for the onset of chronic clinical cardiotoxicity [43].

The model utilized in the present study has already been established in previous publications that included biomarkers of cardiotoxicity as those reported by Beanlands et al. 


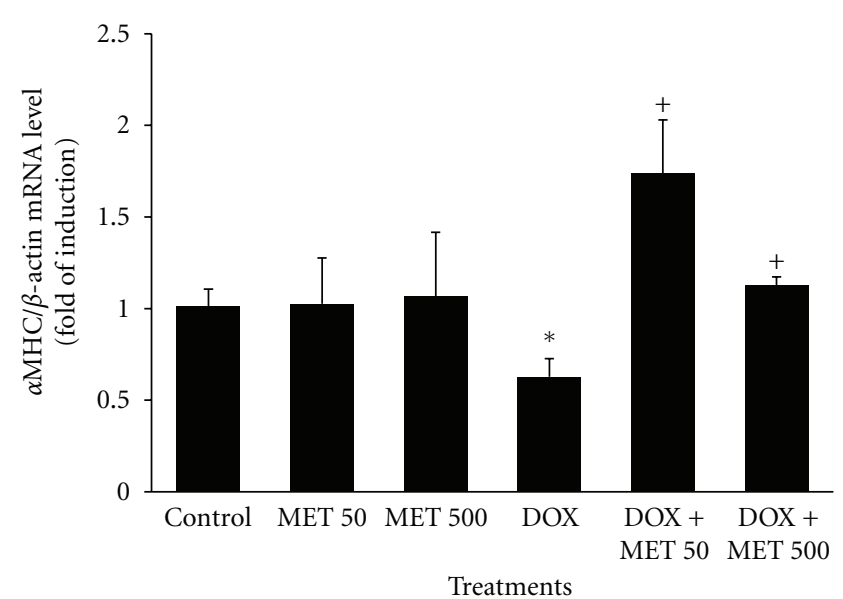

(a)

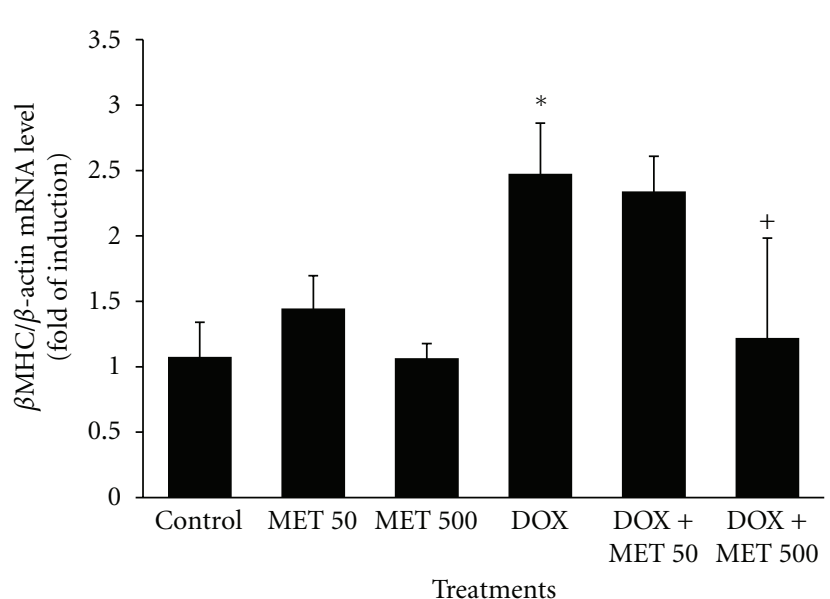

(b)

FIGURE 5: MET reverses DOX-mediated changes in the levels of cardiac hypertrophic genes. Rats $(n=10 /$ treatment type $)$ received normal saline, DOX in a total cumulative dose of $18 \mathrm{mg} / \mathrm{kg}$, MET (50 or $500 \mathrm{mg} / \mathrm{kg}$, p.o., daily), or DOX plus either dose of MET. $24 \mathrm{~h}$ after receiving the last dose of DOX, total RNA was isolated from rat cardiac tissue using TRIzol methods and quantified spectrophotometrically at 260 nm. The mRNA levels of $\alpha$-MHC (a) and $\beta$-MHC genes (b) were quantified using RT-PCR and normalized to $\beta$-actin housekeeping gene. Values represent mean of fold change $\pm \operatorname{SEM}(n=10)$. ${ }^{*} P<0.05$ compared with control rats. ${ }^{+} P<0.05$ compared with DOX-treated rats.

1994 [28] and Sayed-Ahmed et al. 2010 [29]. In the latter study, rats were injected every other day with doxorubicin $(3 \mathrm{mg} / \mathrm{kg}$, i.p.), to obtain treatments with cumulative doses of 6,12 , and $18 \mathrm{mg} / \mathrm{kg}$. The cumulative cardiotoxicity of DOX was clearly featured in that study by the dose-dependent increase in serum cardiac enzymes CK-MB and LDH. At the highest cumulative dose, $18 \mathrm{mg} / \mathrm{kg}$, DOX resulted in a significant increase in CK-MB and LDH and decrease in ATP as well as the expression of apoptotic genes, as compared to the control group. That is why we decided to use that same highest cumulative dose to produce the model of DOXinduced cardiotoxicity on the cellular and molecular levels, rather than functional ones, using the same animal species.

Since DOX causes disruption of cardiac myocyte cell membranes, the release of intracellular proteins, such as $\mathrm{LDH}$ and $\mathrm{CK}-\mathrm{MB}$, into serum has been used to assay for the presence and extent of cardiac myocyte injury $[6,44]$. The levels of these two enzymes were markedly increased by DOX administration in our study. Our results are in a good agreement with previous reports $[45,46]$. In addition, histopathological investigation of cardiac tissues from DOX-treated rats showed myocardial mononuclear chronic inflammation that replaced the degenerated muscle fibers affected. Electron microscopic examination revealed the presence of morphological evidences of mitochondrial injury, as well as myofibrillar loss and disruption. Moreover, treatment with DOX increased $\beta$-MHC expression and decreased $\alpha$ MHC expression, as a result of cardiac toxicity. This is consistent with earlier published data [47-50]. All these biochemical and molecular changes and histopathological deteriorations were completely prevented by MET therapy $(500 \mathrm{mg} / \mathrm{kg}$, every day). These results suggest that MET therapy during DOX treatment for cancer offers substantial protection of the heart against DOX-induced injury. The initial damage caused by DOX is believed to be oxidative in nature. This drug can undergo one electron reduction to the corresponding semiquinone, leading to the generation of superoxide radical [51]. DOX interacts with iron, generating a DOX-ferric iron free radical complex, and the resulting complex catalyzes the conversion of hydrogen peroxide to the highly reactive hydroxyl radical. Hydrogen peroxide, lipid peroxides, superoxide radical, and hydroxyl radical can damage membranes, macromolecules, and mitochondria and may cause direct myocardial injury $[2,51]$. Notably, mammalian hearts are vulnerable to DOX cardiotoxicity due to limited antioxidant mechanisms that could protect them from oxidative injury $[2,52]$.

In the present study, total content of GSH, the most important endogenous antioxidant, was assessed as a marker for oxidative stress, since reduced GSH normally represents more than $90 \%$ of cellular GSH content [53]. The method used in this study utilized Ellman's reagent which determines total $\mathrm{SH}$-containing compounds, which are mainly represented as reduced GSH $[54,55]$. Also, the gene expression of the oxidative stress molecular markers, NQO-1, catalase, HO- 1 , and GST- $\alpha$, has been investigated to elaborate more on the oxidative stress pathway. Moreover, it has been reported that DOX itself causes the disappearance of glutathione peroxidase and significantly lowers the levels of GSH in heart tissue. This diminishes the capability of the heart to dispose of hydrogen peroxide, making the heart more susceptible to redox injury $[51,52,56,57]$. Cardiac tissue level of GSH was demonstrated in our study to be significantly decreased by DOX treatment, which comes in agreement with the previous report by Aleisa et al. [58]. Remarkably, this decrease was completely prevented by the two doses (50 


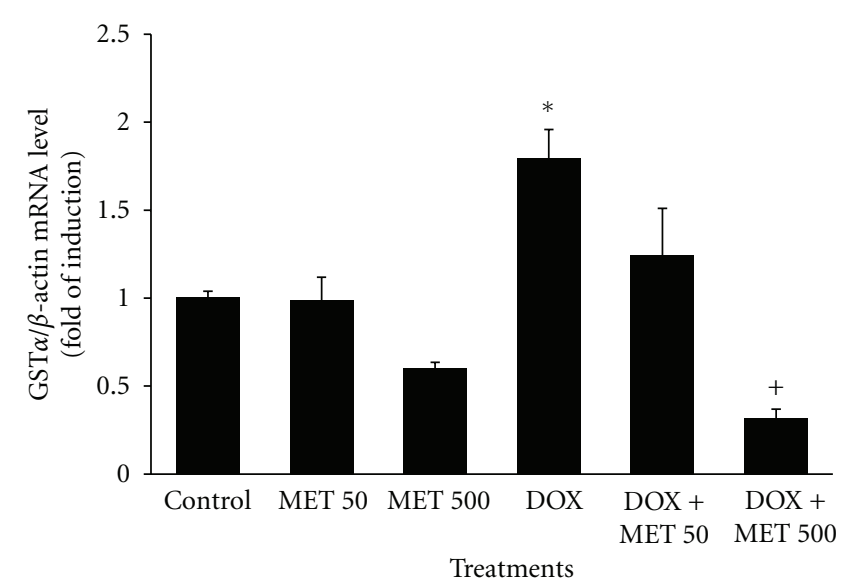

(a)

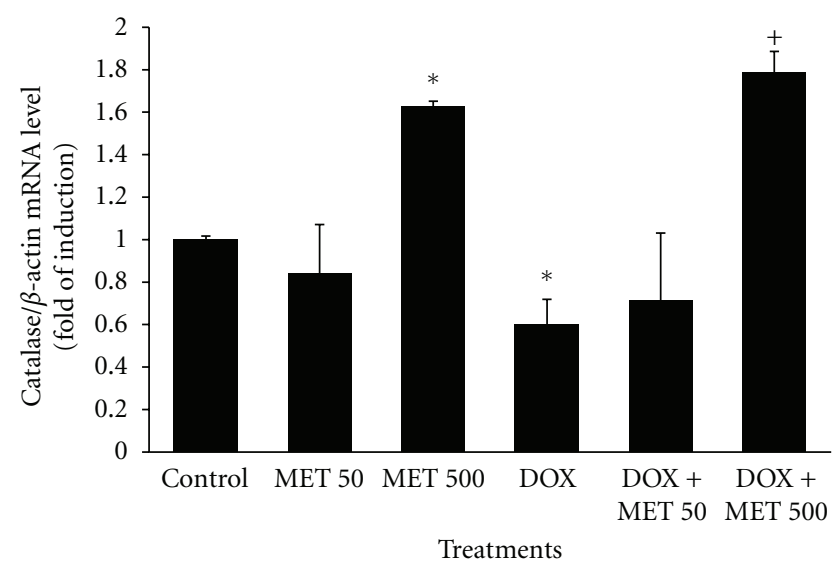

(c)

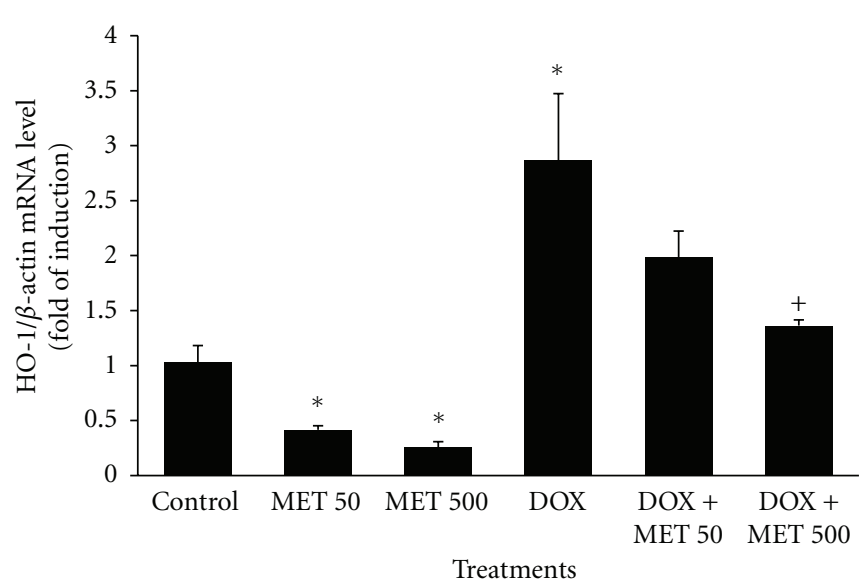

(b)

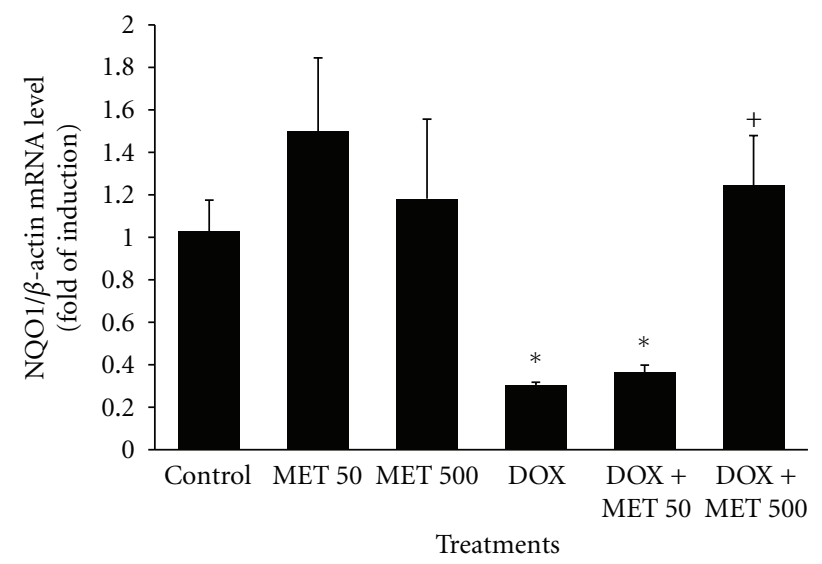

(d)

FIGURE 6: MET restores DOX-mediated changes in the levels of oxidative stress-related genes. Rats $(n=10 /$ treatment type) received normal saline, DOX in a total cumulative dose of $18 \mathrm{mg} / \mathrm{kg}$, MET (50 or $500 \mathrm{mg} / \mathrm{kg}$, p.o., daily), or DOX plus either dose of MET. $24 \mathrm{~h}$ after receiving the last dose of DOX, total RNA was isolated from rat cardiac tissue using TRIzol methods and quantified spectrophotometrically at $260 \mathrm{~nm}$. The mRNA levels of GST $\alpha$ (a), HO-1 (b), CAT (c), and NQO1 (d) were quantified using RT-PCR and normalized to $\beta$-actin housekeeping gene. Values represent mean of fold change $\pm \operatorname{SEM}(n=10) .{ }^{*} P<0.05$ compared with control rats. ${ }^{+} P<0.05$ compared with DOX-treated rats.

and $500 \mathrm{mg} / \mathrm{kg} / \mathrm{d}$ ) of MET, indicating its strong antioxidant activity and its potential cardioprotective efficacy against DOX cardiotoxicity.

DOX also exerted dramatic effects on the expression of molecular oxidative stress markers. It induced the expression of GST $\alpha$ and HO-1 genes and decreased CAT and NQO1 mRNA expression as compared to control rats. DOX treatment is known to enhance the production of the highly reactive lipid peroxidation product 4-hydroxy-2-nonenal (HNE) in cardiac tissue [59]. DOX-induced HNE has been shown to be partially detoxified by conjugation with GSH by GST to form the glutathione conjugate of HNE (GS-HNE) [60]. Induction of GST $\alpha$ gene expression by DOX in the present work reveals that cardiac tissues were defending themselves against DOX toxicity by augmenting the expression of GST $\alpha$ which, in turn, consumed GSH to detoxify DOX. This is evidenced by the significant decrease of cardiac tissue level of GSH by DOX (Figure 2). By virtue of its antioxidant activity, MET released the pressure on cardiac tissue to augment
GST $\alpha$ expression, thereby saving the cardiac levels of GSH (Figure 2).

Moreover, the results showed that CAT, an enzyme responsible for the removal of $\mathrm{H}_{2} \mathrm{O}_{2}$, gene expression is decreased by DOX treatment, supporting the idea that DOX induces a state of oxidative stress in the heart tissues. NQO1 is cytosolic enzyme that plays an essential role in the detoxification of quinones through two-electron reduction process $[61,62]$. In addition, NQO1 helps to maintain endogenous antioxidants, in their active form [63]. It seems that the decrease in NQO1 expression by DOX treatment in our study is attributed to a direct inhibitory effect. This may lead to insufficient NQO1 activity that could have buffered DOXoxidizing properties. Therefore, the heart was highly exposed to oxidizing species induced by DOX. In the same sense, DOX induced HO-1 gene expression which is the ratelimiting enzyme of heme degradation, and it is a stressresponsive protein that responds to many kinds of chemically or physiologically produced oxidative stress, including GSH 
depletion, in various cells and tissues $[64,65]$. Hence, the induction of HO-1 gene expression by DOX could be understood as a response of cardiac cells to DOX-induced GSH depletion. MET, alone or along with DOX, decreased HO- 1 expression. This could be because MET itself possesses a significant antioxidant activity as shown above. The significant increase in the GSH level and CAT and NQO-1 mRNA expression in heart tissue of animals after treatment with MET supports the above hypothesis that MET ameliorates DOX-induced oxidative stress. These results have extended earlier finding by others that MET substantially increased GSH level in normal rats [24] and protected against the DOX-induced decrease of GSH in mice [58]. Interestingly, Faure et al. [24] showed that this effect was independent of MET effect on insulin activity. More recently, AsensioLopez et al. [66] illustrated that MET exerts a protective effect against DOX-induced cardiotoxicity through the involvement of the cardiac system of adiponectin and restoring the activity of antioxidant enzymes in isolated cardiomyocytes in vitro.

The most important role of mitochondria in the myocardium is to supply cardiac cells with ATP, a crucial source of energy for contraction and for the maintenance of ion homeostasis, protein synthesis, and other important cellular functions [67]. In that regard, DOX was shown to inhibit long-chain fatty acid oxidation in the heart [68]. Under physiological conditions, long-chain fatty acids are the favored substrates for energy production in the heart [69]. Consequently, inhibition of long-chain fatty acid oxidation results in a deficiency in ATP supply and accumulation of toxic intermediates including long-chain fatty acyl-CoA thioesters and long-chain acyl-carnitine derivatives in cardiac tissues, with subsequent cardiomyopathy and congestive heart failure [70-72]. In the present study, level of ATP in cardiac tissue was markedly reduced by DOX treatment. In addition, DOX significantly decreased level of CoA-SH, an indispensable activator in most of the energy-providing systems (TCA cycle, fatty acid oxidation) [73], and increased that of acetyl-CoA, the main product of $\beta$-oxidation of fatty acids. Acetyl-CoA is a strong inhibitor of 3-ketoacyl-CoA thiolase, the enzyme catalyzing the last step in $\beta$-oxidation of fatty acids, especially at low concentrations of $\mathrm{CoA}-\mathrm{SH}$ [74]. Therefore, in the present study, raising the acetyl$\mathrm{CoA} / \mathrm{CoA}-\mathrm{SH}$ ratio in isolated rat heart mitochondria by DOX could inhibit fatty acid oxidation, with subsequent deleterious effects on cardiac energy supply. Therapy with MET prevented the decrease of ATP and the increase of acetyl-CoA/CoA-SH ratio induced by DOX. These data indicate that MET protects myocardium against DOX-induced energy starvation and depletion of intramitochondrial CoASH. In that context, Gundewar et al. [27] have recently reported that MET significantly improves left ventricular function and survival via activation of AMPK in a murine model of heart failure. Activated AMPK phosphorylates a variety of intracellular proteins to increase ATP generation and decrease ATP utilization for processes not immediately critical for survival [75].

Collectively, the data presented in this study suggest that liberation of free radicals induced by DOX treatment causes oxidative injury to heart tissues and organelles including mitochondria. Since heart is almost entirely dependent on ATP generated by mitochondria for its function and contractility [76], mitochondrial injury, with its subsequent depression of myocardial ATP, contributes to the progression of cardiac toxicity [77]. The oxidative injury to the heart is accentuated by the reduction of the cardiac antioxidant defense, represented by the great reduction of GSH content and CAT and NQO-1 gene expression induced by DOX. Therefore, our data suggest that the protective effect of MET against DOX-induced cardiac toxicity could originate from its antioxidant activity.

\section{Conclusion}

Results from the present investigation reveal that DOX induces its cardiotoxicity by decreasing cardiac level of CoA$\mathrm{SH}$ and increasing that of acetyl-CoA, with the consequent inhibition of fatty acid oxidation and ATP generation. This is aggravated by the increased susceptibility of the heart to oxidant injury due to DOX-induced reduction of cardiac GSH level, as well as the decrease in CAT and NQO-1 gene expression. Our findings demonstrate that MET prevents all of these biochemical and molecular changes and other histopathological and ultrastructural deteriorations in the cardiac tissues, warranting its coadministration with DOX to ameliorate its cardiotoxicity.

\section{Conflict of Interests}

The authors have no personal or financial conflict of interest and have not entered into any agreement that could interfere with their access to the data on the research or upon their ability to analyze the data independently, to prepare papers, and to publish them.

\section{Acknowledgment}

This work was supported by a grant from the King Abdulaziz City for Science and Technology (KACST; Grant no. ARP29-265). The technical assistance of Mr. Jamal Hardelo from the Department of Pharmacology, College of Medicine, King Saud University, is greatly appreciated.

\section{References}

[1] G. Minotti, P. Menna, E. Salvatorelli, G. Cairo, and L. Gianni, "Anthracyclines: molecular advances and pharmacologie developments in antitumor activity and cardiotoxicity," Pharmacological Reviews, vol. 56, no. 2, pp. 185-229, 2004.

[2] M. S. Horenstein, R. S. Vander Heide, and T. J. L'Ecuyer, "Molecular basis of anthracycline-induced cardiotoxicity and its prevention," Molecular Genetics and Metabolism, vol. 71, no. 1-2, pp. 436-444, 2000.

[3] S. Rajagopalan, P. M. Politi, B. K. Sinha, and C. E. Myers, "Adriamycin-induced free radical formation in the perfused rat heart: implications for cardiotoxicity," Cancer Research, vol. 48, no. 17, pp. 4766-4769, 1988.

[4] F. Rossi, W. Filippelli, S. Russo, A. Filippelli, and L. Berrino, "Cardiotoxicity of doxorubicin: effects of drugs inhibiting. 
The release of vasoactive substances," Pharmacology and Toxicology, vol. 75, no. 2, pp. 99-107, 1994.

[5] T. Simunek, M. Sterba, O. Popelova, M. Adamcova, R. Hrdina, and V. Gersl, "Anthracycline-induced cardiotoxicity: overview of studies examining the roles of oxidative stress and free cellular iron," Pharmacological Reports, vol. 61, no. 1, pp. 154171, 2009.

[6] R. D. Olson and P. S. Mushlin, "Doxorubicin cardiotoxicity: analysis of prevailing hypotheses," The FASEB Journal, vol. 4, no. 13, pp. 3076-3086, 1990.

[7] M. M. Sayed-Ahmed, S. A. Shouman, B. M. Rezk, M. H. Khalifa, A. M. Osman, and M. M. El-Merzabani, "Propionyl-Lcarnitine as potential protective agent against adriamycininduced impairment of fatty acid beta-oxidation in isolated heart mitochondria," Pharmacological Research, vol. 41, no. 2, pp. 143-150, 2000.

[8] V. De Leonardis, B. Neri, S. Bacalli, and P. Cinelli, "Reduction of cardiac toxicity of anthracyclines by L-carnitine: preliminary overview of clinical data," International Journal of Clinical Pharmacology Research, vol. 5, no. 2, pp. 137-142, 1985.

[9] C. F. Seifert, M. E. Nesser, and D. F. Thompson, "Dexrazoxane in the prevention of doxorubicin-induced cardiotoxicity," Annals of Pharmacotherapy, vol. 28, no. 9, pp. 1063-1072, 1994.

[10] A. Puri, S. K. Maulik, R. Ray, and V. Bhatnagar, "Electrocardiographic and biochemical evidence for the cardioprotective effect of vitamin $\mathrm{E}$ in doxorubicin-induced acute cardiotoxicity in rats," European Journal of Pediatric Surgery, vol. 15, no. 6, pp. 387-391, 2005.

[11] I. Morishima, H. Matsui, H. Mukawa et al., "Melatonin, a pineal hormone with antioxidant property, protects against adriamycin cardiomyopathy in rats," Life Sciences, vol. 63, no. 7, pp. 511-521, 1998.

[12] E. Tatlidede, O. Sehirli, A. Velioglu-Ogunc et al., "Resveratrol treatment protects against doxorubicin-induced cardiotoxicity by alleviating oxidative damage," Free Radical Research, vol. 43, no. 3, pp. 195-205, 2009.

[13] E. Delpy, S. N. Hatem, N. Andrieu et al., "Doxorubicin induces slow ceramide accumulation and late apoptosis in cultured adult rat ventricular myocytes," Cardiovascular Research, vol. 43, no. 2, pp. 398-407, 1999.

[14] S. Wang, E. A. Konorev, S. Kotamraju, J. Joseph, S. Kalivendi, and B. Kalyanaraman, "Doxorubicin induces apoptosis in normal and tumor cells via distinctly different mechanisms: intermediacy of $\mathrm{H}_{2} \mathrm{O}_{2}$ - and p53-dependent pathways," Journal of Biological Chemistry, vol. 279, no. 24, pp. 25535-25543, 2004.

[15] A. S. Glicksman and R. W. Rawson, "Diabetes and altered carbohydrate metabolism in patients with cancer," Cancer, vol. 9, no. 6, pp. 1127-1134, 1956.

[16] P. A. Marks and J. S. Bishop, "The glucose metabolism of patients with malignant disease and of normal subjects as studied by means of an intravenous glucose tolerance test," The Journal of Clinical Investigation, vol. 36, no. 2, pp. 254-264, 1957.

[17] M. Deleers and E. Goormaghtigh, "Adriamycin effects on insulin secretion, $\mathrm{Ca} 2+$ movements and glucose oxidation in pancreatic islet cells," Pharmacological Research Communications, vol. 17, no. 3, pp. 227-232, 1985.

[18] J. P. Ioannidis, P. J. Hesketh, and J. Lau, "Contribution of dexamethasone to control of chemotherapy-induced nausea and vomiting: a meta-analysis of randomized evidence," Journal of Clinical Oncology, vol. 18, no. 19, pp. 3409-3422, 2000.

[19] R. E. Coleman, "Glucocorticoids in cancer therapy," Biotherapy, vol. 4, no. 1, pp. 37-44, 1992.
[20] A. Munck, "Glucocorticoid inhibition of glucose uptake by peripheral tissues: old and new evidence, molecular mechanisms, and physiological significance.," Perspectives in Biology and Medicine, vol. 14, no. 2, pp. 265-269, 1971.

[21] Z. Suba and M. Ujpál, "Correlations of insulin resistance and neoplasms," Magyar onkologia., vol. 50, no. 2, pp. 127-135, 2006.

[22] K. Cusi, A. Consoli, and R. A. Defronzo, "Metabolic effects of metformin on glucose and lactate metabolism in noninsulindependent diabetes mellitus," Journal of Clinical Endocrinology and Metabolism, vol. 81, no. 11, pp. 4059-4067, 1996.

[23] A. Klip and L. A. Leiter, "Cellular mechanism of action of metformin,” Diabetes Care, vol. 13, no. 6, pp. 696-704, 1990.

[24] P. Faure, E. Rossini, N. Wiernsperger, M. J. Richard, A. Favier, and S. Halimi, "An insulin sensitizer improves the free radical defense system potential and insulin sensitivity in high fructose-fed rats," Diabetes, vol. 48, no. 2, pp. 353-357, 1999.

[25] G. Kanigur-Sultuybek, M. Guven, I. Onaran, V. Tezcan, A. Cenani, and H. Hatemi, "The effect of metformin on insulin receptors and lipid peroxidation in alloxan and streptozotocin induced diabetes," Journal of Basic and Clinical Physiology and Pharmacology, vol. 6, no. 3-4, pp. 271-280, 1995.

[26] G. S. Bhamra, D. J. Hausenloy, S. M. Davidson et al., "Metformin protects the ischemic heart by the Akt-mediated inhibition of mitochondrial permeability transition pore opening," Basic Research in Cardiology, vol. 103, no. 3, pp. 274-284, 2008.

[27] S. Gundewar, J. W. Calvert, S. Jha et al., "Activation of AMP-activated protein kinase by metformin improves left ventricular function and survival in heart failure," Circulation Research, vol. 104, no. 3, pp. 403-411, 2009.

[28] R. S. B. Beanlands, N. A. Shaikh, W. H. Wen et al., "Alterations in fatty acid metabolism in adriamycin cardiomyopathy," Journal of Molecular and Cellular Cardiology, vol. 26, no. 1, pp. 109-119, 1994.

[29] M. M. Sayed-Ahmed, O. A. Al-Shabanah, M. M. Hafez, A. M. Aleisa, and S. S. Al-Rejaie, "Inhibition of gene expression of heart fatty acid binding protein and organic cation/carnitine transporter in doxorubicin cardiomyopathic rat model," European Journal of Pharmacology, vol. 640, no. 1-3, pp. 143-149, 2010.

[30] P. Anurag and C. V. Anuradha, "Metformin improves lipid metabolism and attenuates lipid peroxidation in high fructose-fed rats," Diabetes, Obesity and Metabolism, vol. 4, no. 1, pp. 36-42, 2002.

[31] X. Wang, X. Jia, T. Chang, K. Desai, and L. Wu, "Attenuation of hypertension development by scavenging methylglyoxal in fructose-treated rats," Journal of Hypertension, vol. 26, no. 4, pp. 765-772, 2008.

[32] S. N. Buhl and K. Y. Jackson, "Optimal conditions and comparison of lactate dehydrogenase catalysis of the lactate to pyruvate and pyruvate to lactate reactions in human serum at 25, 30, and 37॰C.," Clinical Chemistry, vol. 24, no. 5, pp. 828-831, 1978.

[33] A. H. Wu and G. N. Bowers Jr., "Evaluation and comparison of immunoinhibition and immunoprecipitation methods for differentiating $\mathrm{MB}$ from $\mathrm{BB}$ and macro forms of creatine kinase isoenzymes in patients and healthy individuals," Clinical Chemistry, vol. 28, no. 10, pp. 2017-2021, 1982.

[34] A. Longo, G. Bruno, S. Curti, A. Mancinelli, and G. Miotto, "Determination of L-carnitine, acetyl-L-carnitine and propionyl-L-carnitine in human plasma by high-performance liquid chromatography after pre-column derivatization with 
1-aminoanthracene," Journal of Chromatography B, vol. 686, no. 2, pp. 129-139, 1996.

[35] H. E. Botker, H. H. Kimose, P. Helligso, and T. T. Nielsen, "Analytical evaluation of high energy phosphate determination by high performance liquid chromatography in myocardial tissue," Journal of Molecular and Cellular Cardiology, vol. 26, no. 1, pp. 41-48, 1994.

[36] G. L. Ellman, "Tissue sulfhydryl groups," Archives of Biochemistry and Biophysics, vol. 82, no. 1, pp. 70-77, 1959.

[37] S. Granados-Principal, J. L. Quiles, C. L. Ramirez-Tortosa, P. Sanchez-Rovira, and M. Ramirez-Tortosa, "New advances in molecular mechanisms and the prevention of adriamycin toxicity by antioxidant nutrients," Food and Chemical Toxicology, vol. 48, no. 6, pp. 1425-1438, 2010.

[38] K. B. Wallace, "Doxorubicin-induced cardiac mitochondrionopathy," Pharmacology and Toxicology, vol. 93, no. 3, pp. 105-115, 2003.

[39] V. Lee, A. K. Randhawa, and P. K. Singal, "Adriamycin-induced myocardial dysfunction in vitro is mediated by free radicals," American Journal of Physiology, vol. 261, no. 4, part 2, pp. H989-H995, 1991.

[40] M. F. Xu, P. L. Tang, Z. M. Qian, and M. Ashraf, "Effects by doxorubicin on the myocardium are mediated by oxygen free radicals," Life Sciences, vol. 68, no. 8, pp. 889-901, 2001.

[41] S. Zhou, C. M. Palmeira, and K. B. Wallace, "Doxorubicininduced persistent oxidative stress to cardiac myocytes," Toxicology Letters, vol. 121, no. 3, pp. 151-157, 2001.

[42] J. M. Berthiaume and K. B. Wallace, "Adriamycin-induced oxidative mitochondrial cardiotoxicity," Cell Biology and Toxicology, vol. 23, no. 1, pp. 15-25, 2007.

[43] M. Tokarska-Schlattner, T. Wallimann, and U. Schlattner, "Alterations in myocardial energy metabolism induced by the anti-cancer drug doxorubicin," Comptes Rendus, vol. 329, no. 9, pp. 657-668, 2006.

[44] M. Preus, A. S. Bhargava, A. E. Khater, and P. Gunzel, "Diagnostic value of serum creatine kinase and lactate dehydrogenase isoenzyme determinations for monitoring early cardiac damage in rats," Toxicology Letters, vol. 42, no. 2, pp. 225-233, 1988.

[45] M. A. Abd El-Aziz, A. I. Othman, M. Amer, and M. A. ElMissiry, "Potential protective role of angiotensin-converting enzyme inhibitors captopril and enalapril against adriamycininduced acute cardiac and hepatic toxicity in rats," Journal of Applied Toxicology, vol. 21, no. 6, pp. 469-473, 2001.

[46] M. E. Büyükokuroğlu, S. Taysi, M. Buyukavci, and E. Bakan, "Prevention of acute adriamycin cardiotoxicity by dantrolene in rats," Human and Experimental Toxicology, vol. 23, no. 5, pp. 251-256, 2004.

[47] K. Nakao, W. Minobe, R. Roden, M. R. Bristow, and L. A. Leinwand, "Myosin heavy chain gene expression in human heart failure," Journal of Clinical Investigation, vol. 100, no. 9, pp. 2362-2370, 1997.

[48] B. D. Lowes, W. Minobe, W. T. Abraham et al., "Changes in gene expression in the intact human heart: downregulation of $\alpha$-myosin heavy chain in hypertrophied, failing ventricular myocardium," Journal of Clinical Investigation, vol. 100, no. 9, pp. 2315-2324, 1997.

[49] G. Cooper, "Basic determinants of myocardial hypertrophy: a review of molecular mechanisms," Annual Review of Medicine, vol. 48, pp. 13-23, 1997.

[50] B. Swynghedauw, S. Besse, P. Assayag et al., "Molecular and cellular biology of the senescent hypertrophied and failing heart," American Journal of Cardiology, vol. 76, no. 13, pp. 2D7D, 1995.
[51] C. Myers, "The role of iron in doxorubicin-induced cardiomyopathy," Seminars in Oncology, vol. 25, no. 4, supplement 10, pp. 10-14, 1998.

[52] R. D. Olson, J. S. MacDonald, and C. J. VanBoxtel, "Regulatory role of glutathione and soluble sulfhydryl groups in the toxicity of adriamycin," Journal of Pharmacology and Experimental Therapeutics, vol. 215, no. 2, pp. 450-454, 1980.

[53] A. Meister, "Metabolism and functions of glutathione," Trends in Biochemical Sciences C, vol. 6, pp. 231-234, 1981.

[54] A. Meister and M. E. Anderson, "Glutathione," Annual Review of Biochemistry, vol. 52, pp. 711-760, 1983.

[55] A. Meister, "On the discovery of glutathione," Trends in Biochemical Sciences, vol. 13, no. 5, pp. 185-188, 1988.

[56] N. Iliskovic, T. Li, N. Khaper, V. Palace, and P. K. Singal, "Modulation of adriamycin-induced changes in serum free fatty acids, albumin and cardiac oxidative stress," Molecular and Cellular Biochemistry, vol. 188, no. 1-2, pp. 161-166, 1998.

[57] M. Valko, D. Leibfritz, J. Moncol, M. T. Cronin, M. Mazur, and J. Telser, "Free radicals and antioxidants in normal physiological functions and human disease," International Journal of Biochemistry and Cell Biology, vol. 39, no. 1, pp. 44-84, 2007.

[58] A. M. Aleisa, S. S. Al-Rejaie, S. A. Bakheet et al., "Effect of metformin on clastogenic and biochemical changes induced by adriamycin in Swiss albino mice," Mutation Research, vol. 634, no. 1-2, pp. 93-100, 2007.

[59] S. Zhou, A. Starkov, M. K. Froberg, R. L. Leino, and K. B. Wallace, "Cumulative and irreversible cardiac mitochondrial dysfunction induced by doxorubicin," Cancer Research, vol. 61, no. 2, pp. 771-777, 2001.

[60] P. Alin, U. H. Danielson, and B. Mannervik, "4-hydroxyalk-2enals are substrates for glutathione transferase," FEBS Letters, vol. 179, no. 2, pp. 267-270, 1985.

[61] P. Nioi and J. D. Hayes, "Contribution of $\mathrm{NAD}(\mathrm{P}) \mathrm{H}$ :quinone oxidoreductase 1 to protection against carcinogenesis, and regulation of its gene by the Nrf2 basic-region leucine zipper and the arylhydrocarbon receptor basic helix-loop-helix transcription factors," Mutation Research, vol. 555, no. 1-2, pp. 149-171, 2004.

[62] P. Talalay and A. T. Dinkova-Kostova, "Role of nicotinamide quinone oxidoreductase 1 (NQO1) in protection against toxicity of electrophiles and reactive oxygen intermediates," Methods in Enzymology, vol. 382, pp. 355-364, 2004.

[63] K. Iida, K. Itoh, Y. Kumagai et al., "Nrf2 is essential for the chemopreventive efficacy of oltipraz against urinary bladder carcinogenesis," Cancer Research, vol. 64, no. 18, pp. 64246431, 2004.

[64] L. A. Applegate, P. Luscher, and R. M. Tyrrell, "Induction of heme oxygenase: a general response to oxidant stress in cultured mammalian cells," Cancer Research, vol. 51, no. 3, pp. 974-978, 1991.

[65] M. Rizzardini, M. Carelli, M. R. Cabello Porras, and L. Cantoni, "Mechanisms of endotoxin-induced haem oxygenase mRNA accumulation in mouse liver: synergism by glutathione depletion and protection by $\mathrm{N}$-acetylcysteine," Biochemical Journal, vol. 304, no. 2, pp. 477-483, 1994.

[66] M. C. Asensio-Lopez, A. Lax, D. A. Pascual-Figal, M. Valdes, and J. Sanchez-Mas, "Metformin protects against doxorubicin-induced cardiotoxicity: involvement of the adiponectin cardiac system," Free Radical Biology and Medicine, vol. 51, no. 10, pp. 1861-1871, 2011.

[67] L. M. Mela-Riker and R. D. Bukoski, "Regulation of mitochondrial activity in cardiac cells," Annual Review of Physiology, vol. 47, pp. 645-663, 1985. 
[68] S. Abdel-Aleem, M. M. El-Merzabani, M. Sayed-Ahmed, D. A. Taylor, and J. E. Lowe, "Acute and chronic effects of adriamycin on fatty acid oxidation in isolated cardiac myocytes," Journal of Molecular and Cellular Cardiology, vol. 29, no. 2, pp. 789-797, 1997.

[69] J. R. Neely and H. E. Morgan, "Relationship between carbohydrate and lipid metabolism and the energy balance of heart muscle.," Annual Review of Physiology, vol. 36, pp. 413-459, 1974.

[70] R. Bressler, R. Gay, J. G. Copeland, J. J. Bahl, J. Bedotto, and S. Goldman, "Chronic inhibition of fatty acid oxidation: new model of diastolic dysfunction," Life Sciences, vol. 44, no. 25, pp. 1897-1906, 1989.

[71] P. B. Corr, R. W. Gross, and B. E. Sobel, "Amphipathic metabolites and membrane dysfunction in ischemic myocardium," Circulation Research, vol. 55, no. 2, pp. 135-154, 1984.

[72] A. M. Katz and F. C. Messineo, "Lipid-membrane interactions and the pathogenesis of ischemic damage in the myocardium," Circulation Research, vol. 48, no. 1, pp. 1-16, 1981.

[73] G. Peluso, R. Nicolai, E. Reda, P. Benatti, A. Barbarisi, and M. Calvani, "Cancer and anticancer therapy-induced modifications on metabolism mediated by carnitine system," Journal of Cellular Physiology, vol. 182, no. 3, pp. 339-350, 2000.

[74] Y. Olowe and H. Schulz, "Regulation of thiolases from pig heart. Control of fatty acid oxidation in heart," European Journal of Biochemistry, vol. 109, no. 2, pp. 425-429, 1980.

[75] W. W. Winder and D. G. Hardie, "AMP-activated protein kinase, a metabolic master switch: possible roles in Type 2 diabetes," American Journal of Physiology, vol. 277, no. 1, part 1, pp. E1-E10, 1999.

[76] S. Goffart, J. C. von Kleist-Retzow, and R. J. Wiesner, "Regulation of mitochondrial proliferation in the heart: powerplant failure contributes to cardiac failure in hypertrophy," Cardiovascular Research, vol. 64, no. 2, pp. 198-207, 2004.

[77] A. M. Katz, "The myocardium in congestive heart failure," American Journal of Cardiology, vol. 63, no. 2, pp. 12A-16A, 1989. 


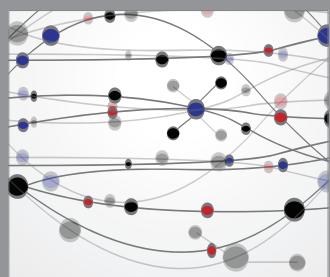

The Scientific World Journal
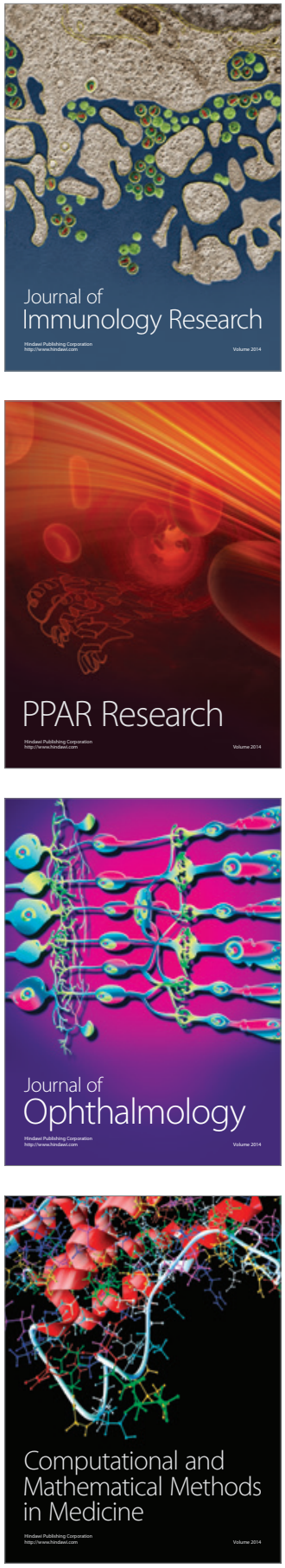

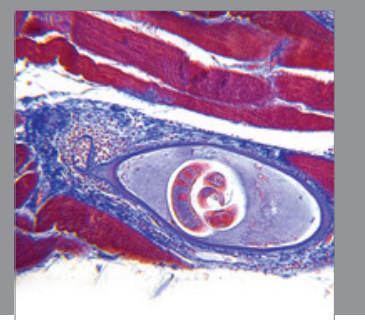

Gastroenterology

Research and Practice
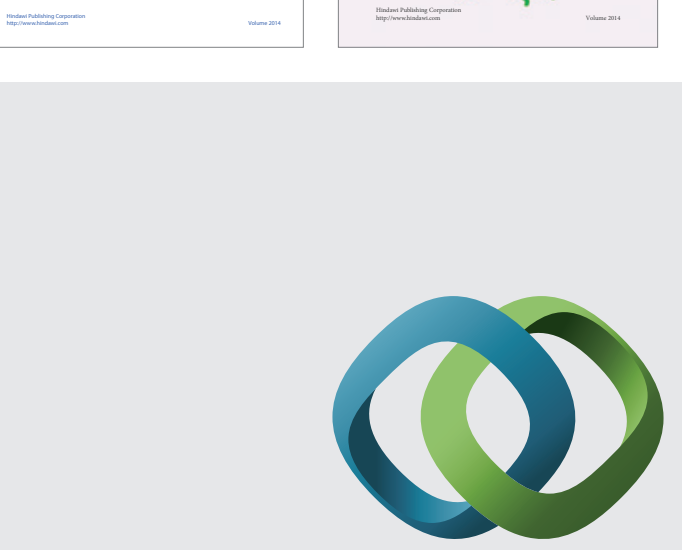

\section{Hindawi}

Submit your manuscripts at

http://www.hindawi.com
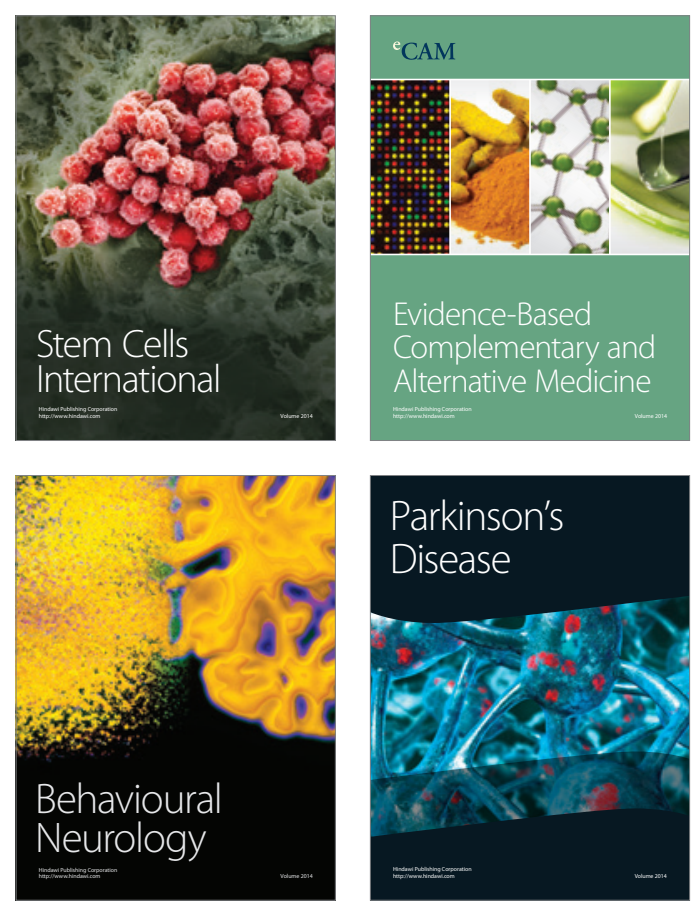

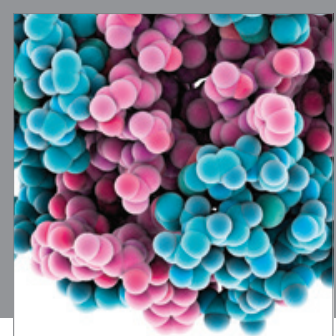

Journal of
Diabetes Research

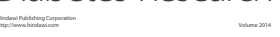

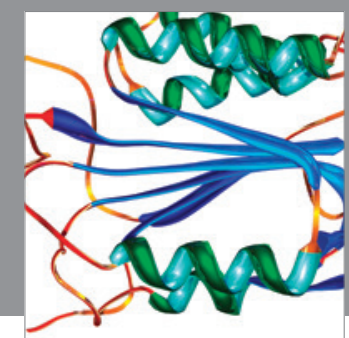

Disease Markers
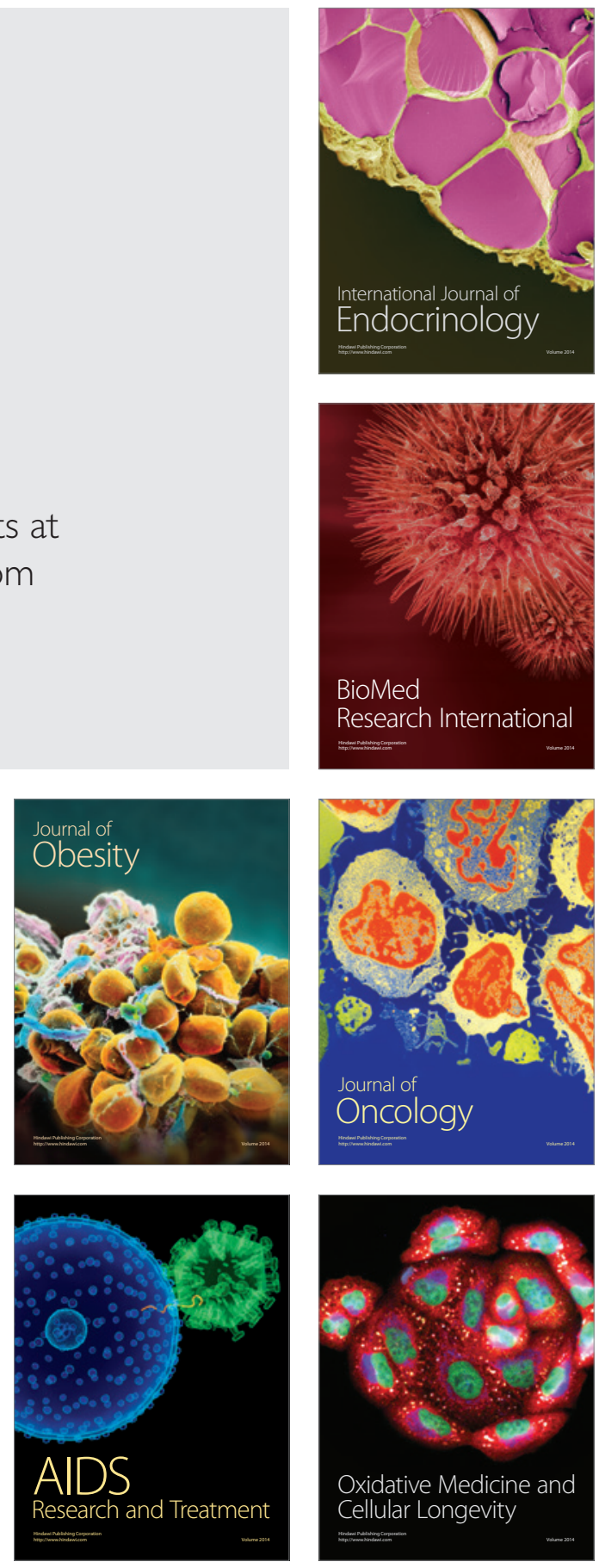